\title{
Efecto del cloruro de calcio sobre la calidad del fruto de uchuva (Physalis peruviana L.)
}

\section{Calcium chloride effect on the quality of the cape gooseberry fruit (Physalis peruviana L.)}

Fecha de recepción: 17 de marzo de 2016

Fecha de aceptación: 13 de junio de 2016

\author{
Elberth Hernando Pinzón-Sandoval ${ }^{1}$ \\ Andrea Johana Reyes ${ }^{2}$ \\ Javier Giovanni Álvarez-Herrera ${ }^{3}$
}

\begin{abstract}
Resumen
La uchuva es uno de los cultivos promisorios en las zonas del trópico alto, debido a las características nutricionales de su fruto; pero este es afectado por desórdenes de tipo fisiológico, entre estos, el rajado, que puede ocasionar hasta el $30 \%$ de pérdidas poscosecha. El rajado se puede presentar por múltiples causas, de las cuales la mas destacada es la deficiencia de calcio en los frutos, debido a la baja movilidad de este vía floema, y la disminución en la relación xilema/floema en este tipo de fruto. El objetivo del trabajo fue evaluar el efecto del cloruro de calcio $\left(\mathrm{CaCl}_{2}\right)$ en el fruto de uchuva, aplicado tanto a este como al cáliz en precosecha, en dosis de $1 \%$ y $2 \%(\mathrm{p} / \mathrm{v})$. Se midió el diámetro ecuatorial y polar, la firmeza, los sólidos solubles totales, la acidez total titulable y el índice de color del fruto, y se hallaron diferencias estadísticas $(\mathrm{P} \leq 0,05)$ en todas las variables, a excepción de la firmeza. Los resultados indican que la aplicación de $\mathrm{CaCl}_{2}$, sin importar la dosis, generó un bloqueo de la maduración del fruto debido, posiblemente, al aumento del calcio en este, el cual disminuyó la actividad respiratoria y la producción de etileno, necesarias para desencadenar procesos de hidrólisis de almidón, degradación de clorofilas, actividad enzimática y degradación de ácidos orgánicos, así, como procesos propios de la maduración del fruto y, por ende, de su calidad organoléptica.
\end{abstract}

Palabras clave: cáliz; desorden fisiológico; maduración; precosecha; promisorio.

\begin{abstract}
The cape gooseberry is one of the promising crops in areas of high tropics, due to the nutritional characteristics presented by this fruit; however, this fruit is affected by disorders of physiological type, among these the fruit cracking, which can cause up to $30 \%$ of post-harvest losses. This cracking can occur

1 M.Sc. Universidad Pedagógica y Tecnológica de Colombia (Tunja-Boyacá, Colombia). elberth.pinzon@uptc.edu.co.

2 Profesional Independiente.

3 Ph.D. Universidad Pedagógica y Tecnológica de Colombia (Tunja-Boyacá, Colombia). javier.alvarez@uptc.edu.co.
\end{abstract}


for many reasons, the most important among them are the fruit calcium deficiency, due to its low mobility via phloem, and the xylem/phloem ratio decrease in this fruit type. This paper objective was to evaluate the effect of calcium chloride $\left(\mathrm{CaCl}_{2}\right)$ applied to both the fruit and the calyx preharvest, in doses of $1 \%$ and $2 \%(\mathrm{w} / \mathrm{v})$. The polar and equatorial diameter, firmness, total soluble solid, total titratable acidity and color index were measured. Statistical differences were found $(P \leq 0.05)$ in all the variables, except firmness. The results indicate that the $\mathrm{CaCl}_{2}$ application, regardless of gender dose blockade the fruit ripening, possibly due to increased calcium in the fruit, which decreased respiratory activity and ethylene production, necessary to trigger starch processes hydrolysis, degradation of chlorophylls, enzyme activity and degradation of organic acids as fruit ripening' own processes and thus, its organoleptic quality.

Keywords: calyx; disorder physiological; preharvest; promissory; ripening. 


\section{Introducción}

La uchuva (Physalis peruviana L.) sitúa su centro de origen en el Perú y está bien distribuida en las zonas altas de Suramérica $(1,2)$. La uchuva pertenece a la familia de las Solanáceas, y es la especie más conocida del género Physalis, que comprende de 75 a 90 especies (3). El cultivo de uchuva es una alternativa de producción para la economía de muchos países, entre estos Colombia, ya que presenta buenas perspectivas e interés en los mercados internacionales, debido a que este fruto es muy apetecido por su sabor y sus propiedades funcionales y medicinales, principalmente, su alto contenido de antioxidantes (ácido ascórbico y provitamina A), fósforo, hierro, proteína y fibra $(4,5)$.

Los principales productores de $P$. peruviana a nivel mundial son: Colombia, Kenia, Zimbabwe, Australia, Nueva Zelanda, India y Ecuador (1). El ecotipo colombiano ha sobresalido en el mercado mundial por su sabor dulce, buen aroma y color brillante característico (6). La producción en Colombia se concentra en los departamentos de Boyacá, Antioquia, Cundinamarca, Nariño y Santander; Boyacá es el mayor productor a nivel nacional, con un área de siembra de 388 ha, un rendimiento de 16.3 t.ha $^{-1} \mathrm{y}$ una producción de $6.354 \mathrm{t}$, concentrada en los municipios de Arcabuco, Ramiriquí y Ventaquemada (7).

Uno de las principales limitantes que presenta el cultivo de uchuva es el denominado rajado del fruto, que consiste en una fractura de la cutícula o epidermis de este, debido a ciertos desórdenes fisiológicos (8). Este problema puede llegar a representar pérdidas de hasta el $30 \%$ del total de los frutos por planta; además, los exportadores pueden descartar del $20 \%$ al $45 \%$ de la fruta en épocas de alta precipitación por esta causa $(9,10)$. Esta fisiopatía se ha atribuido a muchos factores, como variaciones hídricas y problemas nutricionales de calcio, boro y cobre (11); también se ha encontrado que, posiblemente, puede estar relacionada con problemas varietales (12), es decir, con la existencia de gran variedad de genotipos silvestres en Colombia, así como de ecotipos reintroducidos de África que presentan formas y tamaños diferenciados en cuanto al fruto (13).

La deficiencia de calcio ha sido mencionada por numerosos autores como posible causante de fisiopatías relacionadas con la malformación o ruptura de los frutos carnosos (14), debido a que este elemento participa en procesos como la elongación y división celular y la estructuración de la pared celular, al unir las pectinas mediante enlaces cruzados que forman zonas de empalme, y además genera estabilidad de la membrana mediante la unión de los fosfolípidos, por tanto su ausencia puede inducir el rajado (15).

El calcio es un elemento nutricional que por su poca movilidad en la planta llega en pequeñas cantidades al fruto (16); sumado a esto, su concentración disminuye a medida que el fruto crece, debido al cambio en la relación xilema/floema de dicho órgano (17). Lo anterior muestra la necesidad de buscar alternativas para aumentar su contenido en los frutos en etapas tempranas de desarrollo que eviten la aparición de fisiopatías como el rajado. Por esta razón, la presente investigación tuvo como objetivo evaluar el efecto del cloruro de calcio $\left(\mathrm{CaCl}_{2}\right)$ aplicado de forma directa al fruto y al cáliz, en diferentes dosis en precosecha, y observar los cambios que se presentan en las características físicas y químicas de los frutos de uchuva bajo condiciones de campo.

\section{Materiales y métodos}

La fase de campo se llevó a cabo en la finca El Triunfo, vereda La Mesa, municipio de Ventaquemada (Boyacá), ubicada a una altura de $2.630 \mathrm{msnm}$ y con una temperatura promedio de $12{ }^{\circ} \mathrm{C}$. Las pruebas físicas y químicas se realizaron en el Laboratorio de Fisiología Vegetal de la Universidad Pedagógica y Tecnológica de Colombia, sede Tunja, y en el Laboratorio de Poscosecha, de la Universidad Nacional de Colombia, sede Bogotá.

El material vegetal empleado fueron frutos deplantas de uchuva ecotipo 'Colombia', de año y medio de edad, tipo exportación, con una densidad de siembra de 2.000 plantas/ha, y sistema de tutorado 
en ' $\mathrm{V}$ '; el manejo agronómico fue realizado por el productor de acuerdo con las recomendaciones dadas por la empresa exportadora.

Se utilizó un diseño completamente al azar, con cinco tratamientos (Tabla I); cada tratamiento tuvo cuatro repeticiones, correspondiente a 20 unidades experimentales (UE); cada unidad experimental estuvo compuesta por 40 frutos, para un total de 800 frutos. Para la aplicación de los tratamientos se seleccionaron 4 plantas al azar del cultivo por tratamiento, en las cuales se marcaron 50 flores en estado de antesis; a los 35 días después de antesis (dda) se comenzó la aplicación del cloruro de calcio $\left(\mathrm{CaCl}_{2}\right)$, según los tratamientos, repitiendo las aplicaciones cada 8 días hasta completar tres. La cosecha de los frutos se realizó de forma escalonada, ya que algunos de los tratamientos no alcanzaron la madurez comercial. El cloruro de calcio utilizado fue de tipo comercial, con una concentración de $94 \%$, a partir de la cual se realizaron los cálculos para realizar las soluciones.

Tabla I. Tratamientos aplicados durante la precosecha en frutos de uchuva (Physalis peruviana L.).

\begin{tabular}{ccc}
\hline Tratamiento & $\begin{array}{c}\text { Dosis de } \mathbf{C a C l}_{2} \\
\mathbf{\%}(\mathbf{p} / \mathbf{v})\end{array}$ & $\begin{array}{c}\text { Sitio de } \\
\text { aplicación }\end{array}$ \\
\hline 1 & 1 & Cáliz \\
2 & 2 & Cáliz \\
3 & 1 & Fruto \\
4 & 2 & Fruto \\
5 & 0 & Testigo \\
\hline
\end{tabular}

Las variables evaluadas para todos los tratamientos fueron: Diámetro ecuatorial y polar, mediante calibrador Mitutoyo; Índice de color, mediante colorímetro digital Minolta CR310 (Minolta Co., Tokyo), empleando la ecuación [1], en donde: a*: cromaticidad de verde a rojo, $b^{*}$ : cromaticidad de azul a amarillo y $L^{*}$ : luminosidad; Firmeza del fruto $(\mathrm{N})$, mediante un texturómetro digital (Lloyd LS1, Bognor Regis, UK) con celda de carga de $1 \mathrm{KN}$, punzón cilíndrico de $3 \mathrm{~mm}$ y software Nexygen plus; Sólidos solubles totales (SST), a través de la medición de grados Brix con un refractómetro digital (Hanna, Woonsocket, RI) de rango 0 a $85 \%$ con precisión $0.1^{\circ}$ Brix, y la Acidez total titulable, de acuerdo con la metodología de la AOAC (2000), mediante cálculos con datos del volumen de hidróxido de sodio $(\mathrm{NaOH})$ incorporado en 1 g de jugo de frutos más $50 \mathrm{ml}$ de agua destilada y agregando 3 gotas de fenolftaleína como indicador del cambio de color, estos reemplazados en la ecuación [2]. El contenido de calcio en tejido fue obtenido mediante digestión húmeda y absorción atómica realizadas de manera particular por el laboratorio Tecnianalisis S.A.S. Bogotá-Colombia.

$$
\begin{aligned}
& I C=\left(1000 \times a^{*}\right) /\left(L^{*} \times b^{*}\right) \\
& \% \text { Acidez }=\left(A^{*} B^{*} C\right) * 100 / D
\end{aligned}
$$

Los datos obtenidos fueron sometidos a pruebas de normalidad y homogeneidad mediante las pruebas de Shapiro-Wilk y Levene, respectivamente. Comprobados los supuestos se realizó análisis de varianza (ANOVA); las variables que mostraron diferencias estadísticas fueron sometidas a pruebas de comparación de medias de Tukey ( $\mathrm{P} \leq 0.05)$; los análisis se realizaron con el programa estadístico SAS v.9.2e (Institute Inc., Cary,NC).

\section{Resultados y discusión}

\section{A. Diámetro polar y ecuatorial}

Las variables diámetro ecuatorial y polar presentaron diferencias estadísticas $(P \leq 0.05)$. Los valores más altos para estas variables se presentaron en los frutos procedentes de las plantas testigo, los cuales alcanzaron su madurez y tamaño normales con diámetro ecuatorial y polar de $18 \pm 0.02 \mathrm{~mm}$ y $17.9 \pm 0.02 \mathrm{~mm}$, respectivamente, mientras que los tratamientos en los cuales se realizaron aplicaciones de cloruro de calcio, sin importar la dosis, alteraron el crecimiento normal, presentando frutos de tamaño pequeño, con diámetros que oscilaron entre $12.9 \pm 0.2 \mathrm{~mm}$ y $15.1 \pm 1.0 \mathrm{~mm}$ para el diámetro ecuatorial, y $13.1 \pm 0.2 \mathrm{~mm}$ y $15.3 \pm 0.5$ para el diámetro polar (Figuras $1 \mathrm{~A}$ y $1 \mathrm{~B}$ ).

Lo anterior pudo deberse a que las aplicaciones se realizaron directamente tanto al fruto como al cáliz, aumentando la concentración de calcio en dichos órganos (Figura 4B); teniendo en cuenta 
que una de las funciones del calcio es la de inhibir la síntesis de poligalacturonasa, responsable de la degradación de las pectinas (18), se pudo generar un bloqueo de la elongación de la pared celular, impidiendo de esta forma el ingreso normal de agua y carbohidratos al fruto necesarios para sus crecimiento (10).

\section{B. Firmeza}

No se presentaron diferencias significativas en esta variable; sin embargo, el mayor valor se obtuvo en el tratamiento de $2 \%$ de $\mathrm{CaCl}_{2}$ aplicado al fruto, con una firmeza de $15.5 \pm 0.06 \mathrm{~N}$, mientras que en los frutos del tratamiento control (sin aplicación) se obtuvo el menor valor para esta variable, con $11.9 \pm 0.05 \mathrm{~N}$, esto como producto del proceso natural de maduración.

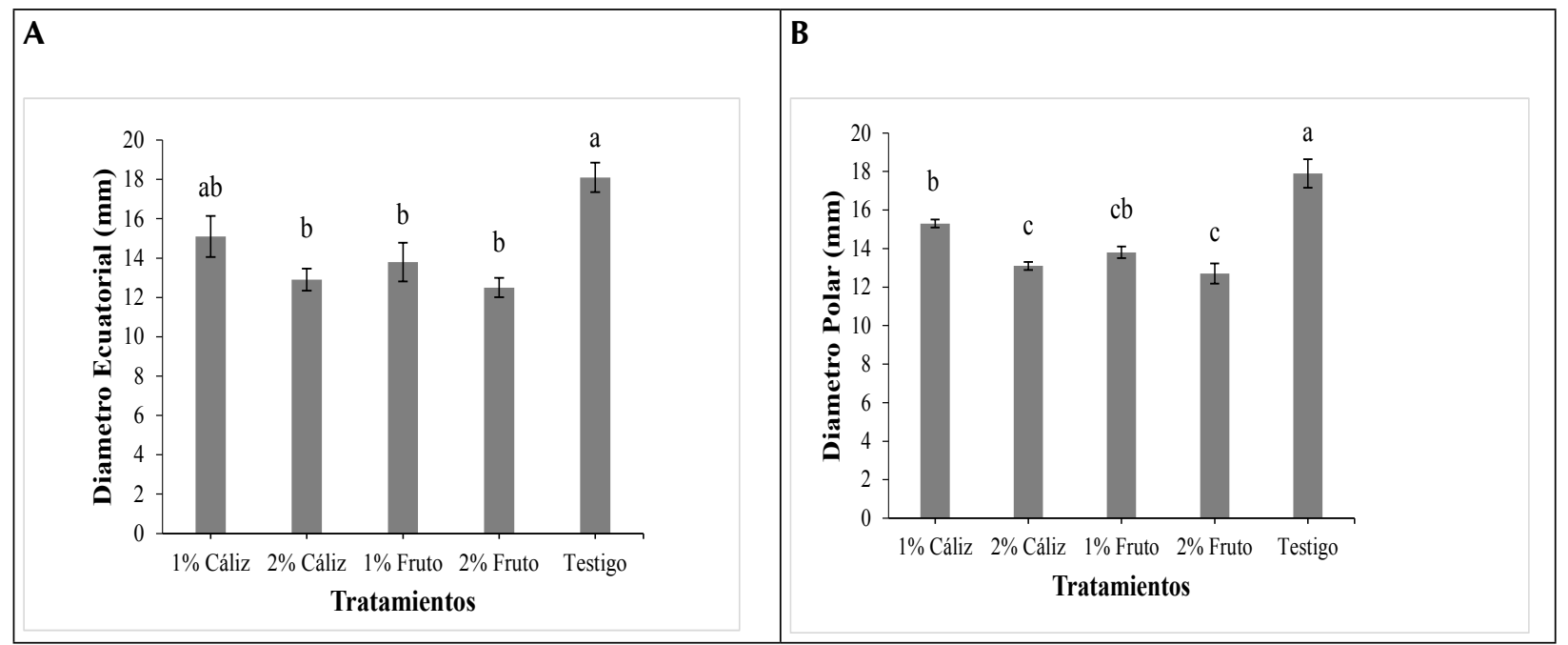

Fig. 1. A. Diámetro Ecuatorial y B. Diámetro Polar de frutos de uchuva (Physalis peruviana L.), con aplicación de $\mathrm{CaCl}_{2}$ al cáliz y al fruto en diferentes dosis. Tratamientos seguidos de letras diferentes presentan diferencias significativas según la prueba de Tukey $(\mathrm{P} \leq 0.05)$, barras verticales indican el error estándar $(\mathrm{n}=4)$.

Se indica que el grado de firmeza de un fruto cambia con el avance del proceso de maduración (19). Los frutos tratados con $\mathrm{CaCl}_{2}$ presentaron menor cambio frente a este parámetro, posiblemente debido al aumento del calcio en el fruto, el cual puede ocasionar disminución en la actividad metabólica y aumentar la estabilidad de la pared celular del fruto. Se ha encontrado que frutos con un buen contenido de calcio presentan aumento en características como la firmeza, que les permite ser transportados más fácilmente y mantener mejores condiciones físicas y químicas luego de cosechados (20). Los resultados encontrados concuerdan con investigaciones realizadas en manzana, las cuales indican que las aplicaciones exógenas de calcio son efectivas para reducir el ablandamiento del fruto (21); esto se debe a que el calcio se une a las cargas negativas de los residuos de ácidos urónicos desesterificados, que son generados por la enzima pectin metil esterasa durante la maduración, aumentando la resistencia mecánica de los tejidos (22). 


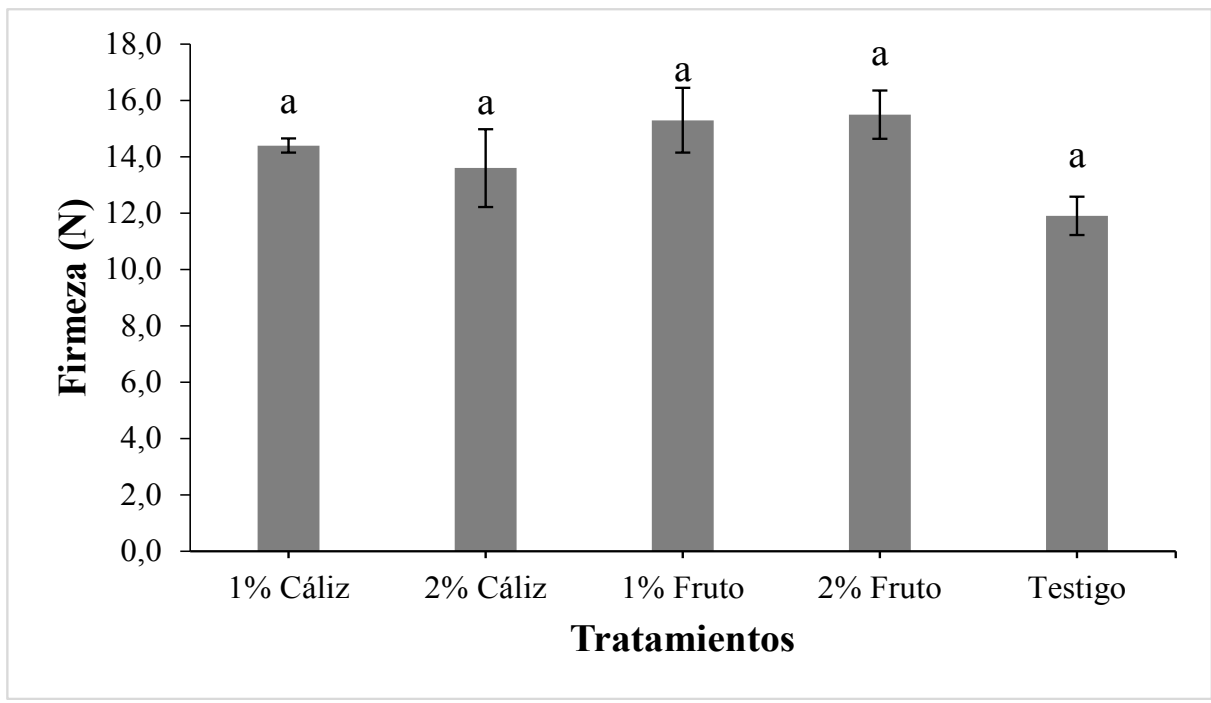

Fig. 2. Firmeza del fruto de uchuva (Physalis peruviana L.), con aplicación de $\mathrm{CaCl}_{2}$ al cáliz y al fruto en diferentes dosis. Tratamientos seguidos de letras diferentes presentan diferencias significativas según la prueba de Tukey $(P \leq 0.05)$, barras verticales indican el error estándar $(n=4)$.

\section{Sólidos solubles totales (SST)}

Se presentaron diferencias significativas $(\mathrm{P} \leq 0.05)$ en relación con los SST. Los tratamientos de 1 $\%$ de $\mathrm{CaCl}_{2}$ al cáliz y sin aplicación presentaron valores de $13.8 \pm 0.4{ }^{\circ}$ Brix y $13.3 \pm 0.04{ }^{\circ}$ Brix, respectivamente, mientras que el tratamiento de 2 $\%$ de $\mathrm{CaCl}_{2}$ aplicado al fruto mostró un valor de $10.4 \pm 0.15^{\circ}$ Brix, siendo este el menor valor de SST (Figura 3). Lo anterior evidencia que los frutos con la aplicación de $2 \%$ de $\mathrm{CaCl}_{2}$, tanto al cáliz como al fruto, sufrieron una alteración notoria al proceso de maduración; las aplicaciones directas a dichos órganos aumentaron de forma notoria los contenidos de calcio en el fruto (Figura 4B), pudiéndose afectar procesos como la actividad respiratoria y la producción de etileno. Se indica que una de las funciones más importantes del calcio en el citosol es la regulación de la actividad respiratoria (20). Los frutos con altos contenidos de $\mathrm{Ca}^{+2}$ disminuyen notoriamente la tasa respiratoria, así como la producción de etileno, actividades que son fundamentales en la conversión del almidón y de los polisacáridos de la pared celular mediante hidrólisis, que dan origen a azúcares solubles como disacáridos y monosacáridos $(23,24)$. Los resultados encontrados contrastan con estudios realizados en frutos de arándano, en los que se evaluó la aplicación de diferentes fuentes de calcio en precosecha y en los cuales no se evidenciaron diferencias en cuanto al contenido de sólidos solubles totales del fruto (25); esto, posiblemente, influenciado por el estado fenológico, la forma de aplicación y el producto utilizado. 


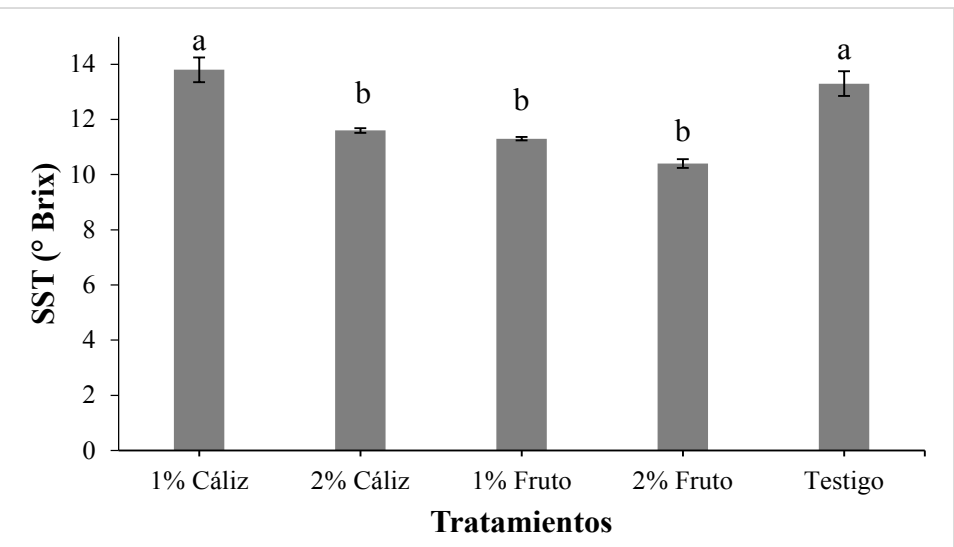

Fig. 3. Sólidos Solubles Totales del fruto de uchuva (Physalis peruviana L.), con aplicación de $\mathrm{CaCl}_{2}$ al cáliz y al fruto en diferentes dosis. Tratamientos seguidos de letras diferentes presentan diferencias significativas según la prueba de Tukey $(P \leq 0.05)$, barras verticales indican el error estándar $(n=4)$.

\section{Acidez total titulable}

Esta variable mostró diferencias estadísticas $(\mathrm{P} \leq 0.05)$ entre los tratamientos, siendo el tratamiento de $2 \%$ de $\mathrm{CaCl}_{2}$ al fruto el que presentó mayor valor en esta variable, con $0.81 \pm 0.04$ (Figura 4A). De acuerdo con algunos estudios realizados en uchuva, se espera que la acidez disminuya durante el proceso de maduración (26, 27), pero esto no concuerda con lo observado en el presente estudio, ya que la aplicación de cloruro de calcio, en cualquier dosis y en el cáliz o en el fruto, ocasionó un comportamiento anormal de este parámetro. La variable ATT se relaciona con lo observado en la variable SST, que presentó los valores más bajos con el tratamiento de 2 $\%$ de $\mathrm{CaCl}_{2}$ al fruto, posiblemente, debido a la disminución de la actividad respiratoria, producto del aumento de $\mathrm{Ca}^{+2}$ en las células del fruto (Figura 4B); disminución que puede generar un bloqueo de la conversión de ácidos orgánicos. La respiración es fundamental en la disminución de los ácidos orgánicos, ya que mediante este proceso estos son utilizados como sustratos o son convertidos en azúcares mediante gluconeogénesis $(27,28)$.

La aplicación directa de cloruro de calcio en las diferentes dosis generó un aumento del calcio en el fruto (Figura 4B); esto explica el comportamiento de las demás variables evaluadas. Se indica que leves aumentos en el calcio citosólico pueden llevar a la disminución de la actividad de enzimas, como la poligalacturonasa y la pentil-metil- esterasa, y a la limitación de la entrada de iones como el $\mathrm{K}^{+}$, el cual es fundamental para la homeostasis celular, debido al aumento del potencial osmótico celular ligado al proceso de crecimiento del fruto (18).

Es posible que los procesos metabólicos disminuyan al aumentar el calcio en el fruto, lo que lleva a una alteración en la maduración de este (29). Estudios realizados en feijoa y litchi indican que existe una relación inversa entre las concentraciones de calcio y los procesos de maduración de los frutos $(29,30)$, lo cual concuerda con lo observado en el presente estudio.

\section{E. Índice de color}

Se presentaron diferencias significativas entre tratamientos $(P \leq 0.05)$, teniendo en cuenta que el índice de color se calculó en función del espacio CIELab, que se basa en el modelo de los colores opuestos y define cada color a partir de unas coordenadas denominadas $L^{*}$ (luminosidad: 0 [negro] a 100 [blanco]), a* (" +60 " [intensidad de color rojo] y "-60" [de color verde]) y b* (" +60 " [intensidad de color amarillo] y "-60" [de color azul]), según el método de Grassmann (31). 


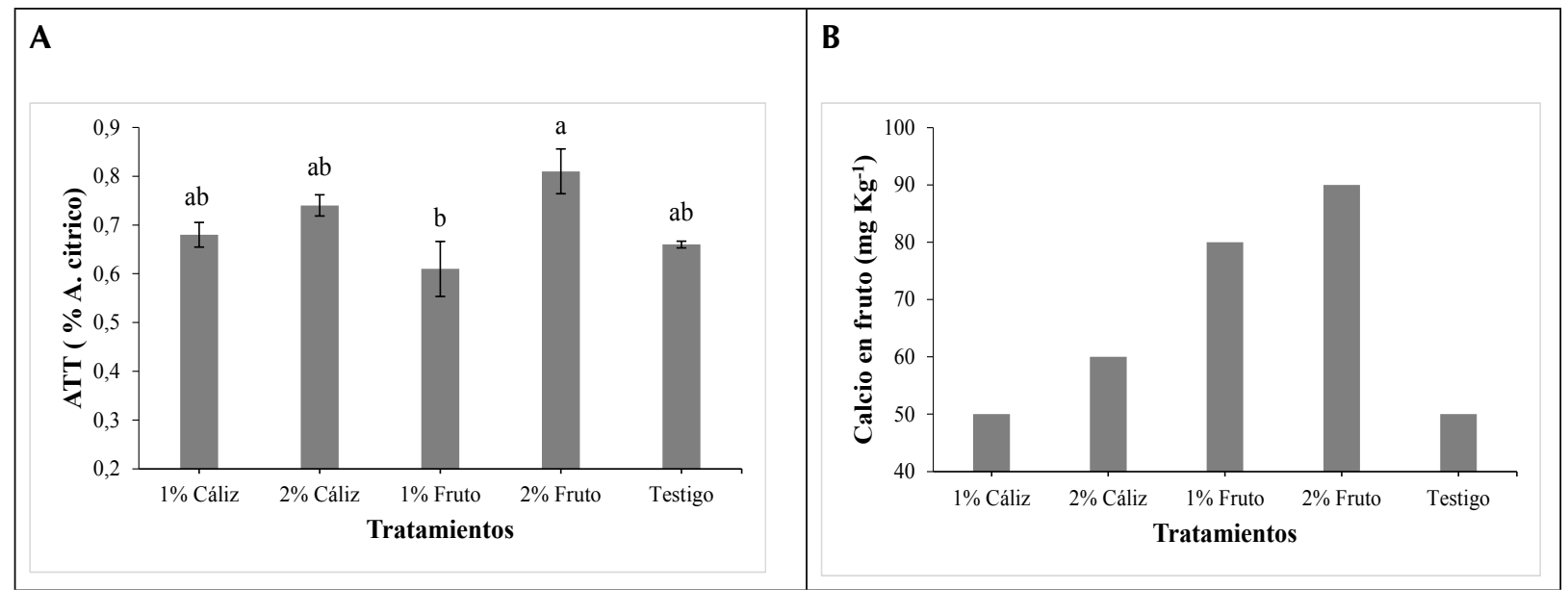

Fig. 4. A. Acidez total titulable; B. Calcio en tejido, del fruto de uchuva (Physalis peruviana L.), con aplicación de $\mathrm{CaCl}_{2}$ al cáliz y al fruto en diferentes dosis. Tratamientos seguidos de letras diferentes presentan diferencias significativas según la prueba de Tukey $(\mathrm{P} \leq 0.05)$; barras verticales indican el error estándar $(n=4)$.

Se pudo observar que la aplicación de $\mathrm{CaCl}_{2}$ disminuyó el índice de color, presentándose frutos de color verde a nivel de epidermis, a diferencia del tratamiento testigo, con el que se observó un cambio de color normal, logrando frutos de color verde-amarillo, que es el tomado como índice de cosecha por el agricultor (Figura 5). Los cambios de color del fruto de uchuva se deben a la degradación de la clorofila y a la acumulación de carotenoides en plástidos (32), principalmente $\beta$-caroteno (33). El cambio de color ha sido relacionado por algunos autores con el aumento del etileno, el cual desencadena reacciones de degradación de clorofilas (34), proceso que, como se mencionó anteriormente, pudo ser bloqueado por el aumento del calcio en los tejidos del fruto (Figura 4B).

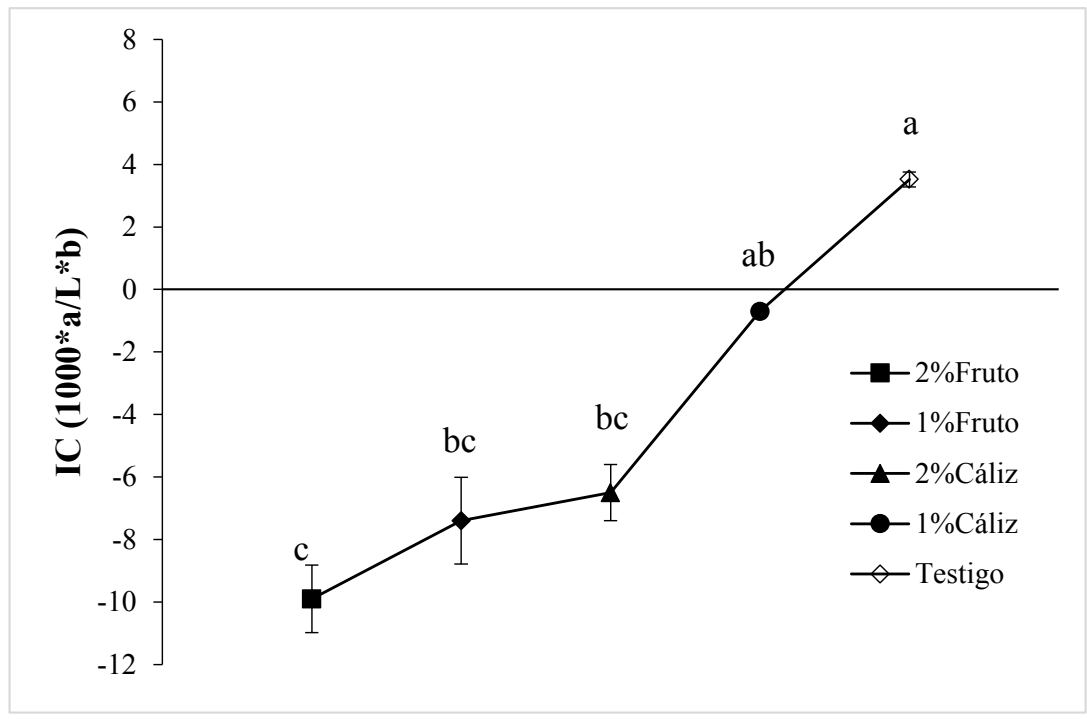

Fig. 5. Índice de color del fruto de uchuva (Physalis peruviana L.), con aplicación de $\mathrm{CaCl}_{2}$ al cáliz y al fruto en diferentes dosis. Tratamientos seguidos de letras diferentes presentan diferencias significativas según la prueba de Tukey $(95 \%)$, barras verticales muestran el error estándar $(n=4)$. 


\section{Conclusiones}

La aplicación de cloruro de calcio tanto al fruto como al cáliz, en dosis de $1 \%$ y $2 \%$ generó un efecto adverso sobre el desarrollo del fruto, afectando características físicas, como el diámetro, la firmeza y el índice de color, y químicas, como los SST, ATT y el contenido de calcio en el fruto; esto generó un bloqueo de la mayoría de los procesos propios de la maduración. Sin embargo, se puede concluir que la aplicación de calcio de manera directa tanto al fruto como al cáliz presentó un efecto notorio sobre el órgano, lo que lleva a pensar que dosis más bajas a las aplicadas podrían contribuir de forma notoria al rajado del fruto sin afectar sus características físicas y químicas.

\section{Agradecimientos}

AlProgramadeFormación deJóvenes Investigadores Colciencias, convocatoria Jóvenes Investigadores e Innovadores Colciencias-2013 'Virginia Gutiérrez Pineda'; a la Dirección de Investigaciones (DIN) de la Universidad Pedagógica y Tecnológica de Colombia (UPTC), por la beca de investigación otorgada, y al Grupo de Investigaciones Agrícolas, por el soporte para la realización del proyecto.

\section{Referencias}

(1) Fischer G, Almanza-Merchán PJ, Miranda D. Importancia y cultivo de la uchuva (Physalis peruviana L.). Rev. Bras. Frutic. Jaboticabal. 2014; 36(1): 1-15. DOI: http://dx.doi. org/10.1590/0100-2945-441/13.

(2) Legge AP. Notes on the history, cultivation and uses of Physalis peruviana L. Journal of the Royal Horticultural Society, London. 1974; 99(7): 310-314.

(3) Whitson M, Manos P. Untangling Physalis (solanaceae) from the Physaloids: a two-gene ohykigeny of the physalinae. Syst. Bot. 2005; 30(1): 216-230. DOI: http://dx.doi. org/10.1600/0363644053661841.

(4) Fischer G, Herrera A, Almanza P. Cape gooseberry (Physalis peruviana L.) In: Yahia,
E.M. (Ed.). Postharvest biology and technology of tropical and subtropical fruits. Acaito citrus, pp. 374-396. Cambridge: Woodhead Publishing. 2011. DOI: http://dx.doi. org/10.1533/9780857092762.374.

(5) Gastelum D. Demanda nutrimental y manejo agronómico de Physalis peruvianum L. Tesis de Maestría. Institución de Enseñanza e Investigación en Ciencias Agrícolas, Texcoco, México. 2012.

(6) Galvis A, Fischer G, Gordillo P. Cosecha y poscosecha de la uchuva. En: Fischer G, Miranda D, Piedrahíta W, Romero J. (Eds.). Avances en cultivo, poscosecha y exportación de la uchuva (Physalis peruviana L.) en Colombia, pp. 165-190. Bogotá: Universidad Nacional de Colombia. 2005

(7) Ministerio de Agricultura y Desarrollo Rural MADR-. Anuario estadístico de frutas y hortalizas 2007-2011. 2012 (Fecha de acceso 20 de marzo de 2016) Disponible en: http://www. agronet.gov.co/www/htm3b/public/Anuario/ anuario $\%$ 20estadistico $\% 20$ de $\% 20$ frutas $\% 20$ y\%20hortalizas\%202011.pdf.

(8) Cooman A, Torres C, Fischer G. Determinación de las causas del rajado del fruto de uchuva (Physalis peruviana L.) bajo cubierta: II. Efecto de la oferta de calcio, boro y cobre. Agron. Colomb. 2005; 23(1): 74-82.

(9) Gordillo O, Fischer G, Guerrero R. Efecto del riego y de la fertilización sobre la incidencia del rajado en frutos de uchuva (Physalis peruviana L.) en la zona de Silvania (Cundinamarca). Agron. Colomb. 2004; 22(1): 53-61.

(10) Fischer G. El problema del rajado del fruto de uchuva y su posible control. En: Fischer G., Miranda D, Piedrahita W, Romero J. (Eds.). Avances en cultivo, poscosecha y exportación de la uchuva (Physalis peruviana L.) en Colombia, pp. 55-82. Bogotá: Universidad Nacional de Colombia. 2005. 
(11) Torres C, Cooman A, Fischer G. Determinación de las causas del rajado del fruto de uchuva (Physalis peruviana L.) bajo cubierta. I. Efecto de la variación del balance hídrico. Agron. Colomb. 2004; 22(1): 140-146.

(12) Criollo T, Lagos C, Fischer G, Mora L, Zamudio L. Comportamiento de tres genotipos de uchuva (Physalis peruviana L.) bajo diferentes sistemas de poda. Rev. Colomb. Cienc. Hortic. 2013; 8(1): 34-43. DOI: http://dx.doi. org/10.17584/rcch.2014v8i1.2798.

(13) Trillos O, Cotes J, Medina C, Lobo M, Navas A. Caracterización morfológica de cuarenta y seis accesiones de uchuva (Physalis peruviana L.) en Antioquia (Colombia). Rev. Bras. Frutic. 2008; 30(3): 708-715. DOI: http://dx.doi. org/10.1590/S0100-29452008000300025.

(14) Lane W, Meheriuk M, McKenzie D. Fruit cracking of a susceptible, an intermediate, and a resistant sweet cherry cultivar. HortScience. 2000; 31(2): 239-242.

(15) Carpita N. Importancia especial de la pared celular en el desarrollo de las plantas. En: Salisbury, F.B. y C.W. Ross (eds.), Fisiología vegetal, pp. 368-370. México: Grupo Editorial Iberoamérica. 1994.

(16) Ramezanian A, Rahemi M, Vazifehshenas MR. Effects of foliar application of calcium chloride and urea on quantitative and qualitative characteristics of pomegranate fruits. Sci. Hortic. 2009; 121: 171-175. DOI: http://dx.doi.org/10.1016/j.scienta.2009.01.039.

(17) Awang Y, Azlan M, Ghani A, Sijam K, Mohamad R. Effect of calcium chloride on anthracnose disease and postharvest quality of redflesh dragon fruit (Hylocereus polyrhizus). Afr. J. Microbiol. Res. 2011; 5: 52505259.

(18) Marschner P. Mineral Nutrition of Higher Plants. 3nd. Edition. Elsevier. Oxford, UK. 2012.
(19) Hernández R, Lobo M, González M. Aptitud al procesado mínimo de cuatro cultivares de mango (Mangifera indica L.). En: Alonso de la Torre, S.R. (coord.). Avances de la Ciencia y Tecnología de los Alimentos en los inicios del siglo XXI, pp. 445448. Universidad de Burgos, España. 2005.

(20) Agustí M. Fruticultura. En: Agusti M. (ed.). Fruticultura. 2 ed. Madrid: Mundi-Prensa. 2010.

(21) Saftner RA, Barden CL, Conway WS, Abbott JA. Effects of 1- methylcyclopropene and heat treatments on ripening and postharvest decay in 'Golden Delicious' apples. Journal of American Society for Horticultural Science. 2003; 128: 120-127.

(22) Magee RI, Caporaso F, Prakash A. Effects of exogenous calcium salt treatments on inhibiting irradiation-induced softening in diced Roma tomatoes. J. of Food Science. 2003; 68(8): 2430-2435. DOI: http://dx.doi.org/10.1111/j.1365-2621.2003.tb07041.x.

(23) Kays S. 2004. Postharvest biology. En: Kays, S. (ed.). ExonPress, Athens: GA.

(24) Menéndez O, Lozano S, Arenas M, Bermúdez K, Martínez A, Jiménez A. Cambios en la actividad de $\alpha$-amilasa, pectinmetilesterasa y poligalacturonasa durante la maduración del maracuyá amarillo (Passiflora edulis var. flavicarpa Degener). Interciencia, Caracas, 2006; 31(10): 728-733.

(25) Manríquez T, Quezada H, Lobos W. Efecto de aplicaciones de calcio en la calidad de la fruta de arándano alto (Vaccinium corymbosum L.) cv. Elliot. IDESIA. 2011; 29(3): 5964. DOI: http://dx.doi.org/10.4067/S071834292011000300009.

(26) Fischer G, Martínez O. Calidad y madurez de la uchuva (Physalis peruviana L.) en relación con la coloración del fruto. Agron. Colomb. 1999; 16(1-3): 35-37. 
(27) Kader AA. Postharvest technology of horticultural crops. University of California, Agricultural and Natural Resources, Publication 3311. Oakland, CA. 2002.

(28) Balaguera-López H, Martínez C, Herrera A. Papel del cáliz en el comportamiento poscosecha de frutos de uchuva (Physalis peruviana L.) ecotipo Colombia. Rev. Colomb. Cienc. Hortic. 2014; 8(2): 181-191. DOI: http://dx. doi.org/10.17584/rcch.2014v8i2.3212.

(29) Ramírez J, Galvis J, Fischer G. Maduración postcosecha de la feijoa (Acca sellowiana Berg) tratada con $\mathrm{CaCl} 2$ en tres temperaturas de almacenamiento. Agron. Colomb. 2005; 23(1): 117-127.

(30) Xu X, Wu Z, Chen W, Su M. Effect of low temperatura on relative enzyme activity and membrane peroxidization of lychee fruits. Acta Horticulturae, 2005; 665: 359-364. DOI: http://dx.doi.org/10.17660/ActaHortic.2005.665.44.

(31) Ramírez S. Espectrocolorimetría: caracterización de leche y quesos. Tecnología Láctea. Latinoamericana. 2010; 61: 52-68.
(32) Trinchero G, Sozzi GO, Cerri AM, Vilella F, Franschina A. Ripening-related changes in ethylene production respiration rate and ceIl-wall enzyme activity in golden berry (Physalis peruviana L.) a solanaceous species. Postharv. Biol. and Technol. 1999; 16: 139145. DOI: http://dx.doi.org/10.1016/S09255214(99)00011-3.

(33) Fischer G, Ebert G, Lüdders P. Provitamin A carotenoids, organic acids and ascorbic acid content of cape gooseberry (Physalis peruviana L.) ecotypes grown at two tropical altitudes. ActaHorticulturae. 2000; 531: 263-267. DOI: http://dx.doi.org/10.17660/ActaHortic.2000.531.43.

(34) Valdenegro M, Fuentes L, Herrera R, Moya-León $M$. Changes in antioxidant capacity during development and ripening of goldenberry (Physalis peruviana L.) fruit and in response to 1-methylcyclopropene treatment. Postharv. Biol. Technol. 2012; 67: 110-117. DOI: $\quad$ http://dx.doi.org/10.1016/j.postharvbio.2011.12.021. 